Article

\title{
Gender-Responsive Public Transportation in the Dammam Metropolitan Region, Saudi Arabia
}

\author{
Muhammad Ahmad Al-Rashid ${ }^{1}\left(\mathbb{D}\right.$, Kh Md Nahiduzzaman $^{2, *} \mathbb{D}^{\mathbb{D}}$, Sohel Ahmed ${ }^{3}{ }^{(\mathbb{D}}$, \\ Tiziana Campisi ${ }^{4 *} *$ (D) and Nurten Akgün ${ }^{5}$ (D) \\ 1 Department of City and Regional Planning, University of Management and Technology, Lahore 54770, \\ Pakistan; ahmad.rashid@umt.edu.pk \\ 2 School of Engineering, University of British Columbia (UBC) Okanagan, Kelowna, BC V1V 1V7, Canada \\ 3 Independent Consultant and Researcher, Edinburgh EH9 3DN, UK; sohel_j_ahmed@yahoo.co.uk \\ 4 Faculty of Engineering and Architecture, Kore University of Enna, Cittadella Universitaria, 94100 Enna, Italy \\ 5 Department of Civil Engineering, Faculty of Engineering and Natural Sciences, Bursa Technical University, \\ 16330 Bursa, Turkey; nurten.akgun@btu.edu.tr \\ * Correspondence: Kh.Nahiduzzaman@ubc.ca (K.M.N.); tiziana.campisi@unikore.it (T.C.)
}

Received: 15 September 2020; Accepted: 27 October 2020; Published: 31 October 2020

check for updates

\begin{abstract}
The limited availability of public transportation in Saudi Arabia leads to an increased demand for private vehicles. An increase in using private cars does not meet the global sustainability goals, e.g., reducing energy consumption and improving the air quality. Road users should be encouraged to use sustainable mobility modes, particularly public transportation, equally accessible to both men and women However, women's mobility has been somewhat limited and challenged in spatio-temporal terms, and partly due to socio-cultural barriers. This study attempts to understand the gender experience of a sample of public transport users and consider their aspirations and needs into daily mobility. A survey campaign (structured interviews and online questionnaires) was launched in the Dammam Metropolitan Region (DMR), taking four different types of respondents into account. The results suggest a predominant preference for taxis for shopping and leisure activities due to a poor public transport service, pivotally characterized by limited operational routes, hours, and infrastructure. This study ponders upon the adequacy of the supporting infrastructures and interior design of the public buses to women's needs and compare them with global best practices. The results suggest that, due to the absence of a gender-responsive design and infrastructure, women are forced to use taxis, although privacy and a sense of insecurity often become concerns when traveling alone or with children. The study results allow future research to be expanded, considering women's mobility patterns, needs, and embedded barriers by comparing the results with current transport policies, plans, and practices.
\end{abstract}

Keywords: public transportation; gender-responsive design; sustainable mobility; gendered need; Saudi Arabia

\section{Introduction}

A sensible and sustainable transport system provides an opportunity for mobility and is commonly regarded as an imperative for access to socio-economic resources [1]. Traditionally, transport researchers have primarily focused on the technological and monetary dimensions of mobility. Increased awareness of the value that mobility brings renders it an encapsulation of liberty [2]. There is also a recognition of studying the social context of mobility to ensure freedom and independence rather than just improving transport infrastructure [3]. Recognizing the social dimensions of mobility are particularly essential for women who carry specific travel needs [4,5]. The role of public transportation, in this regard, 
is quite evident in providing adequate access to opportunities and can give a credible solution for all disadvantaged people at risk of exclusion [6]. Furthermore, addressing the gender-responsive aspect of public transportation, i.e., considering women's needs, can significantly facilitate mobility and participation in daily activities [7-9].

Contrarily, in Middle Eastern countries, a limited focus on public transportation has advocated people's reliance on private vehicles in meeting everyday mobility needs. A recent study [10] conducted in the Kingdom of Saudi Arabia suggests that the majority $(70.4 \%)$ of the women use a private car, followed by taxis $(22.5 \%)$, walking $(3.0 \%)$, and public buses $(2.2 \%)$. It implies that women do not have different mobility choices in the Kingdom [11]. There is also a lack of interest in providing public transportation among urban transport authorities, and their practices dominate technocratic approaches [2]. Moreover, socio-cultural needs, e.g., privacy, safety, comfort, mothers traveling with babies and strollers, etc., affecting women's mobility, have not been considered in public transport plans [12]. Given the current status quo, the women in Saudi Arabia experience an inequality in their mobility; however, there is a lack of empirical research showing women's everyday mobility experiences [11].

This research aims to study and underscore the importance of gender-responsive public transportation in the context of the Dammam Metropolitan Region, Saudi Arabia, by taking into account women's needs. It implies that women's unique cultural and social contexts and needs should be highlighted to adapt this concept and reduce mobility inequality. Therefore, the claim is established by analyzing the factors that inhibit women's mobility and emphasize the exclusionary mechanism associated with public transportation use. Such a discourse calls for a constructivist perspective, as it suggests that human experience is intersubjective, relational, and twined into essential personal and cultural chains [13]. Therefore, this paper acknowledges that, just as gender is socially constructed, mobility with public transportation is relational and is driven from a social perspective [14]. This research also highlights women's diversified need for public transportation and proposes a gendered-based audit that could reduce inequality associated with their daily mobility

This paper is organized as follows: The next section highlights the importance and needs for gender-responsive public transportation. Section 3 provides a brief description of the study context and research methodology, followed by the results. The last part offers concluding thoughts and suggestions.

\section{Gender-Responsive Public Transportation}

Urban transportation should meet road users' needs and provide a sustainable travelling environment [15]. Sustainable urban transportation development plays a significant role in societies, because it improves accessibility for all communities, women being in the first place [16]. Sustainable transport systems, particularly public transportation, gives an opportunity for people to access economic and social facilities [17]. However, women in many countries cannot benefit from this opportunity due to socio-cultural or infrastructural barriers.

Women experience and perceive cities differently from men and use public spaces discretely [18]. It suggests the importance of gender responsiveness that entails paying attention to women's particular needs, valuing and honoring women's perspectives, recognizing women's developmental differences, and ultimately empowering women [19]. Hence, gender-responsive public transport involves transit services that are sustainable, secure, affordable, and ensures equal access to essential resources [20].

Existing travel behavior research is abounding with evidence illustrating the difference between women's and men's transportation realities and demands [21]. It is also widely recognized that women's travel patterns are different from men, and these differences are characterized by profound and insistent inequalities [22]. It depicts women's clear and separate treatment due to the differentiated nature of access and attitudes to private and public transport [23]. Several critical elements reflect the unique travel characteristics and the need for gender responsiveness in public transportation. For instance, personal security is the foremost concern that limits women's mobility significantly [24]. Women are the targets of sexual assaults in the available transport provision $[23,25]$. These factors 
severely jeopardize women's everyday mobility, particularly for the ones associated with domestic work and child-caring responsibilities [26].

Moreover, the built environment characteristics, including the association of land use, physical layout, and network design, affect women and men differently in a significant manner [24,27]. The women hold different expectations, like the easiness and comfort in accessing and approaching the public transit facilities, such as footpaths and vehicles [28]. Hence, women face particular dangers in cities and mobility problems in terms of the built environment [29], as they require unique infrastructure while traveling during pregnancy and along with their children. However, women who have access to cars more likely use them to make trips on others' behalf, carrying children and teenagers to after-school events and providing transport to housebound elderly relatives [30].

In addition to the situational contexts, women's trip scheduling is more complicated than men's, especially when they have dependent children at home, creating more spatio-temporal restrictions and complex travel time budgets [31]. Such journeys are often undertaken outside the rush hour and are more likely to be on foot or by public transport [32]. As compared to men, women tend to devote a significant amount of their time to the activities focusing on household maintenance [33]. Bianco and Lawson [34] mentioned that women are more dependent on automobiles than men because of their dual responsibilities of childcare and household maintenance.

Similarly, laws in some countries (for example, Saudi Arabia) also constrain women's travel and work outside the home [12]. The legal and socio-cultural constructs restrict women primarily to household and caretaking responsibilities, which ultimately makes them often make short but more frequent trips [33], thus indicating that women's urban mobility is not just about developing transport infrastructure and services but about overcoming the social, economic, political, and physical barriers to movement, such as class, gender relations, poverty, physical disabilities, and affordability [6]. So, instead of ignoring the concept of vertical equity, women's travel needs should be associated with the physical environment and social and cultural norms of particular areas [23,35].

The criticality here lies in a sheer understanding of gender-responsive needs and sophistication and reflecting that into the design of public transit services and associated infrastructure. It could only be made possible if women's mobility needs are adequately addressed during the planning process. Against this backdrop, Skidmore and Craig [36] suggested that effective and active participation in transport decision-making should place people at the center of the process. So, there must be an understanding of the lives they lead, the values they hold, the relationships they care about, and the interests that motivate them [36].

These fundamental insights would help transport planning and policy-making a much more people-focused orientation [1]. Ultimately, when women's issues are kept at the center of project planning, the inherent inequality would be eliminated [37]. It is likely that, by incorporating the gender-responsive aspects within the transportation plans, women's needs will have a natural priority, which can ultimately help improve their transport access [28].

The gender perspective, as an essential part of urban planning, is well recognized $[37,38]$. Yet, categorically women's travel needs are often ignored in urban planning and design practices. A visible service variability in the daily mobility for women and men is a fact in the cities of developed countries [23]. However, a thorough study on the daily mobility or travel behavior in line with gender-responsive aspects is pervasively missing in developing countries [22]. Similarly, the prevalence of such a demonstration is significantly low in the cities of Middle Eastern countries. The Kingdom of Saudi Arabia is a pertinent case where women have limited mobility and face an inequality to get access to public transportation that cater to their needs [39]. A lack of adequate public transportation facilities within the Kingdom makes the matter even worse [11].

Saudi Arabian Public Transport Company (SAPTCO) is the only state-run bus that currently functions on minimal routes in the major cities of Saudi Arabia [40]. Such a limited nature of operations is an outcome of the critical shortfalls. For example, the bus routes are short enough to serve the entire cities, and the routes are not demand-driven but the result of an arbitrary plan, or not sufficiently 
integrated with the public transport options of the adjoining towns. Besides, state-sponsored financial subsidy on fuel prices allows people to choose private vehicles over public transportation, i.e., SAPTCO buses [41]. Given the higher subsidy on fuel, private cars have a greater affinity [42,43]. Furthermore, the comfort, privacy, convenience, and time independency associated with such private trips hold firm this demand.

Massive investments are made on public transportation by SAPTCO via periodical projects [39]. Yet, they severely lack an understanding of the gender-responsive aspects, e.g., privacy, convenience, need of a child caring mother, and comfort [44]. Although SAPTCO buses run through the city, its limited operational times and routes as well as inadequate, inaccessible, and lack of gender-responsive infrastructure facilities, e.g., bust stops, adjoining sidewalks, etc., force the women not to use that service. Additionally, the socio-cultural norms, such as privacy, a condition with historical, religious, and cultural importance in Saudi Arabia, severely affect women's mobility and travel patterns [12,43,45-48].

As per the socio-culturally constructed norm, women in Saudi Arabia cannot travel or fly long distances alone without the permission of the family head. In this regard, Nihal [49] mentioned that the women population in Saudi Arabia only travel via taxi due to the absence of male family members or a private driver or car that meets their needs, which might further enhance the privacy and safety concerns. It turns out that women remain immobile, i.e., stay home for a significant portion of the day-from 10 a.m. until 5 p.m.-when they could have been mobile to perform daily activities, including grocery shopping, picking up kids from school, and other purpose-oriented trips. Factually, they need to wait for any male family members, e.g., father, brother, or husband, so that they could give them rides [45]. Thus, all the mentioned barriers result in restricted activities and socio-economic participation among women.

Regardless of such prevailing issues with women's mobility in Saudi Arabia, there remains a wide research gap in the understandings of gender-responsiveness in public transportation. So, there is a need to study the right mode choices that will cater to the women populations that are getting more educated than men and are actively participating in the country's economic growth [43]. Given the literature discussed above, the present study provides novel insights into women's mobility and gender-responsive issues using existing public transport services in a less-discussed Saudi Arabian context.

\section{Materials and Methods}

Regarding the state-of-the-art review given in the previous section, the overall aim of this study was to gain a fundamental understanding of the gendered experience of a sample of public transport users and consider their aspirations and needs into daily mobility. A survey was carried out to collect the dataset in the case study area, the Dammam Metropolitan Region (DMR) in the Kingdom of Saudi Arabia (KSA). The DMR is located within the Eastern Province of the country and includes major cities, including Dammam, Khobar, and Dhahran (Figure 1).

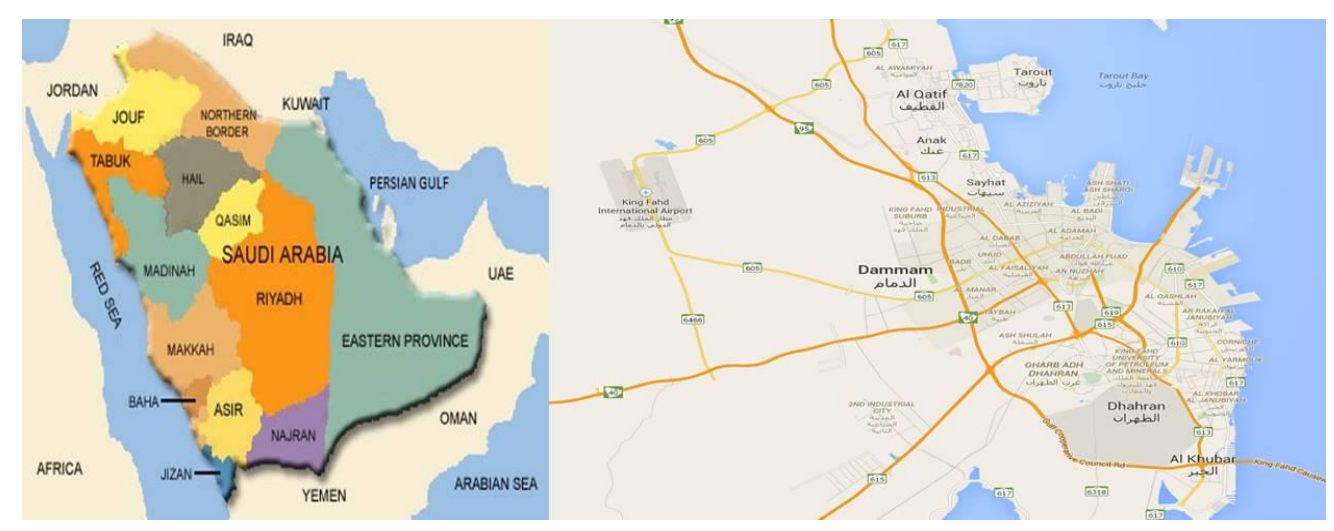

Figure 1. Location map of the Dammam Metropolitan Region in Saudi Arabia. 
The Eastern Province carries some of the biggest oil fields, which significantly contributes to the economic growth of the Kingdom. The DMR is the central exporting point for petroleum and natural gas within the Eastern Province. Therefore, this region has undergone substantial urban development within a brief period. According to the Central Department of Statistics of the KSA, the DMR has experienced rapid population growth during the last three decades [45,49] (Figure 2).

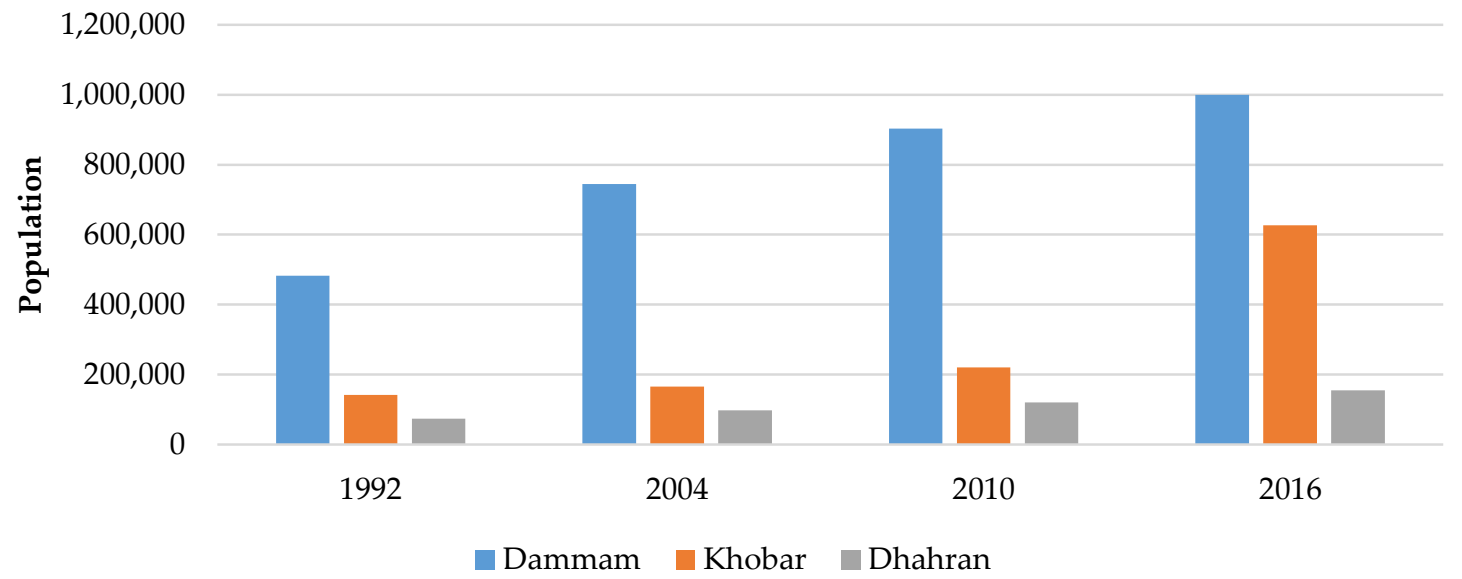

Figure 2. Population demographics of three cities in the DMR, KSA.

In connection with this development, the local public transport also was improved with the new investments. For instance, SAPTCO has provided the intra-city public transport in the DMR. However, the relatively high economic status of the citizens in this region encourages heavy car usage [45]. Moreover, the low quality of the limited public transportation does not meet the residents' mobility needs. Figure 3 shows that the only public transport route (SAPTCO bus) is around $24 \mathrm{~km}$ along a single alignment. Thus, due to the limited public transport infrastructure, the women population of the region also tend to use private vehicles [11,45]. Similarly, the typical travel mode for women, who do not own personal cars, is a taxi available around the region during any time in a day. Moreover, ref. [10] found that taxis are far more preferred than public transport due to accessibility and comfort.

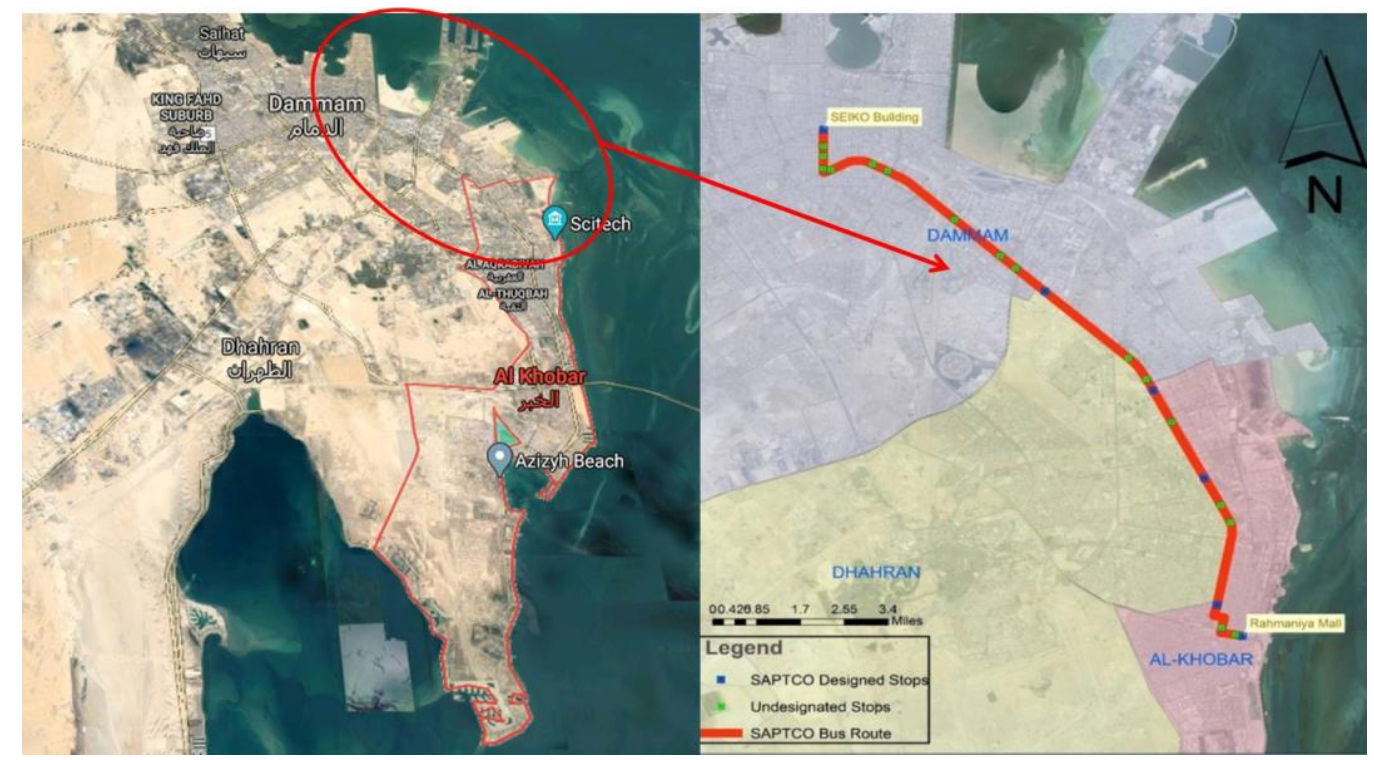

Figure 3. SAPTCO bus route map from the Rahmaniya Mall in Khobar to the SEIKO Building in Dammam. 
The royal decree was issued in May 2018, allowing women to drive and travel across the cities and countries independently [39]. Besides, an online portal was also launched, where women who have already obtained their driving license in other countries can apply for a Saudi driver's license. In response, women-only driving schools have already been established in all major cities of the Kingdom, including DMR, and more are to be opened. However, independent driving is still at the initial phases, and women are still dependent on drivers (private car or taxi) or other adult male members of the family [44,45], which requires improvements in existing public transportation of the DMR. Hence, to provide better insights into women's mobility, a survey campaign was launched in the DMR.

The study is cross-sectional and the survey data were collected from four different respondents, including a women population, employees of the SAPTCO and Dammam Municipality, and the taxi drivers. Among all four respondents, the data were collected using semi-structured questionnaires. Furthermore, the questionnaires were translated into Arabic to deal with the respondents' language barriers, particularly for the women and municipal officials.

Conducting interviews with women were highly challenging due to the socio-cultural issues of the Kingdom. Hence, we utilized the email directory of the DMR citizens, and the questionnaires were sent through Google Forms to 300 women. In turn, 104 responses were received. The responses received from the women participants made it possible to explore socio-demographic variables, mobility needs, travel habits, preferences and attitudes, and barriers to access to the current public transportation modes in the DMR. The women's choices towards the potential gender-responsive and women-only public transport mode were also explored from the responses. Moreover, interviews with 20 different taxi drivers were carried out for obtaining more in-depth information about women's mobility. The taxi drivers' responses helped us explore the travel frequency, the nature of usage, and prime mobility timings with taxis.

The data from officials of the Dammam Municipality and SAPTCO were collected via face-to-face semi-structured interviews. These officials provided information about public transportation, their efforts towards its improvement, and their perceptions about gender-responsive public transportation. It helped to explore the actions and role of the authorities in the provision of efficient public transit infrastructure in the DMR. Table 1 provides the detailed characteristics of the variables that were included in the survey questionnaire.

Table 1. Characteristics of the variables collected during the survey.

\begin{tabular}{|c|c|c|c|c|}
\hline \multirow[b]{2}{*}{ Participant } & & \multirow[b]{2}{*}{ Variables } & \multicolumn{2}{|c|}{ Question Types } \\
\hline & & & $\begin{array}{l}\text { Multiple } \\
\text { Choice }\end{array}$ & $\begin{array}{l}\text { Likert Scale } \\
\text { Rating (1-5) }\end{array}$ \\
\hline \multirow{10}{*}{ Women } & 1 & Age, education, income, and occupation & $\checkmark$ & \\
\hline & 2 & Travel characteristics (mode, purpose, and frequency) & $\checkmark$ & \\
\hline & 3 & Reason for the preference of a mode & $\checkmark$ & \\
\hline & 4 & Availability of the number of private cars for the entire day & $\checkmark$ & \\
\hline & 5 & Mode choice in case of non-availability of private car & $\checkmark$ & \\
\hline & 6 & Barriers in using public transportation & $\checkmark$ & \\
\hline & 7 & Level of personal security in using different modes & & $\checkmark$ \\
\hline & 8 & Reasons for feeling unsafe while using the bus and taxi & $\checkmark$ & \\
\hline & 9 & Overall satisfaction with different transport modes & & $\checkmark$ \\
\hline & 10 & Potential mode of public transportation for women & $\checkmark$ & \\
\hline \multirow{3}{*}{$\begin{array}{l}\text { SAPTCO and } \\
\text { Municipality } \\
\text { Officials }\end{array}$} & 1 & Focus on gender-responsive issues while planning public transport & $\checkmark$ & \\
\hline & 2 & Reasons for the restricted mobility of women with public transport & $\checkmark$ & \\
\hline & 3 & Potential mode of public transportation for women and their roles & $\checkmark$ & \\
\hline Taxi Drivers & 1 & $\begin{array}{c}\text { Travel characteristics of women (such as purpose and frequency, } \\
\text { timings, traveling alone or accompanying children or male adults) } \\
\text { during office hours }\end{array}$ & $\checkmark$ & \\
\hline
\end{tabular}


Applied sensitivity analyses for the study of individual variables and their correlation play an essential role in verifying the robustness of a study's conclusions. Indeed, if the results remain robust under different hypotheses, methods, or scenarios, this can strengthen their reliability and validity. Hence, the analytical method started with a preliminary analysis to examine women participants' age, income, and education level, followed by an understanding of women's mobility needs and barriers towards using the SAPTCO bus.

The results were subsequently compared with the best practices adopted in the study area.

The differences and criticalities were outlined, proposing a gender audit prototype framework and some ideas for future research on assessing the mitigation of the impacts of the analyzed topic. The graphical description provided in Figure 4 summarizes the methodological steps and the survey campaign.

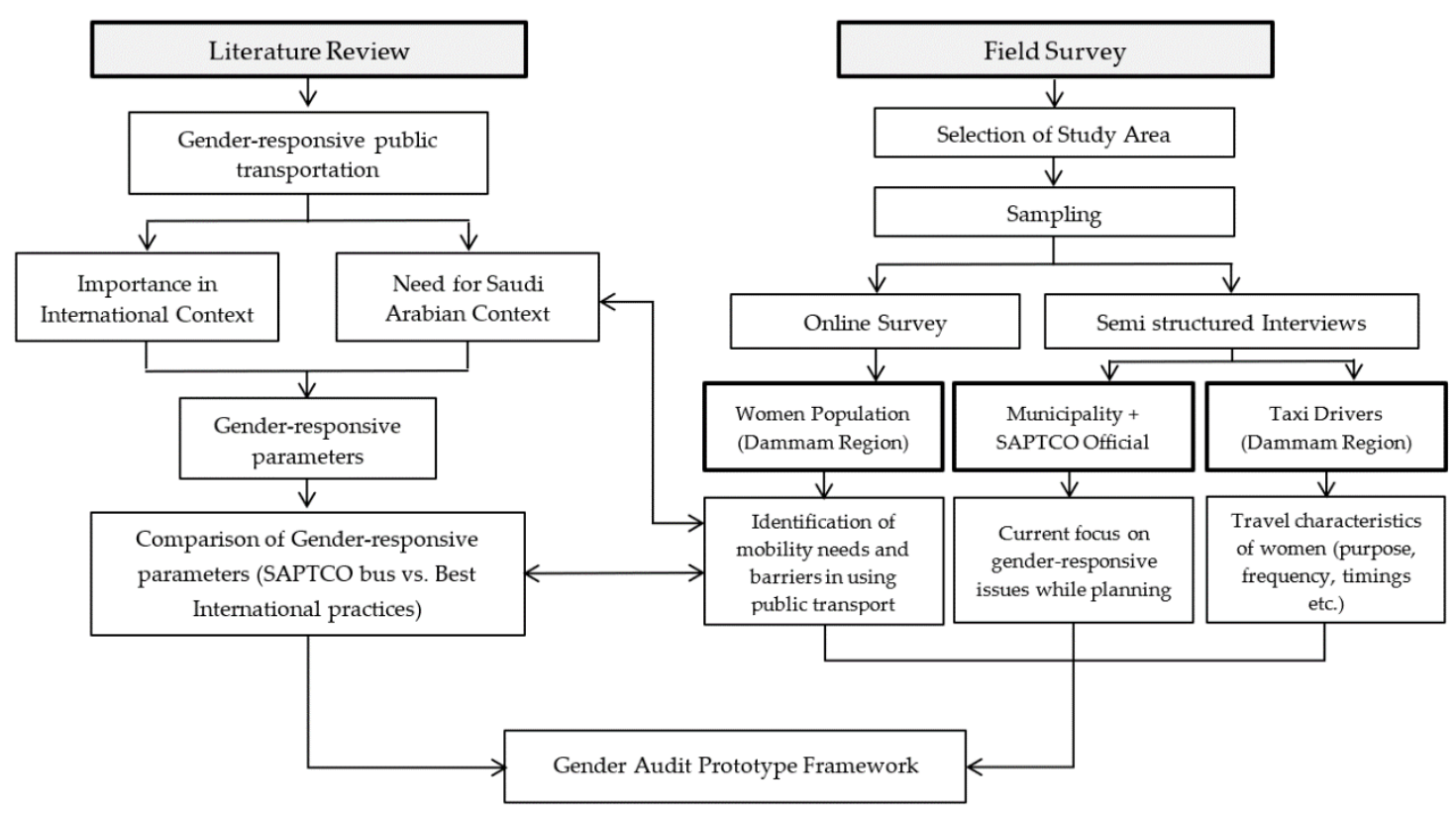

Figure 4. Graphical description of the research methodology and survey campaign.

\section{Study Results}

\subsection{Preliminary Analysis of the Data of the Women Respondents}

As mentioned in the previous section, the survey data was collected from 104 women respondents. The dataset included women respondents aged from 12 to 56 (Figure 5). There was a high representation of women aged between 19 and $26(42.3 \%)$.

However, the number of respondents was found to be decreasing with an increasing age. Results also showed that approximately $40 \%$ of the respondents had a monthly income of less than 5000 Saudi Arabian Riyal (SAR).

A total of $78 \%$ of the respondents had university graduation, followed by high school with $18 \%$ (Figure 6). A total of $32 \%$ of the respondents had a full-time professional activity while $31 \%$ were housewives and $29 \%$ were students.

To sum up, it was seen that the majority of the respondents were young and educated professionals. It was an advantage to better understand the respondents' daily travel needs because they had active mobility.

An approximately equal number of students, homemakers, and working-class women also assisted in eliminating biased results. 


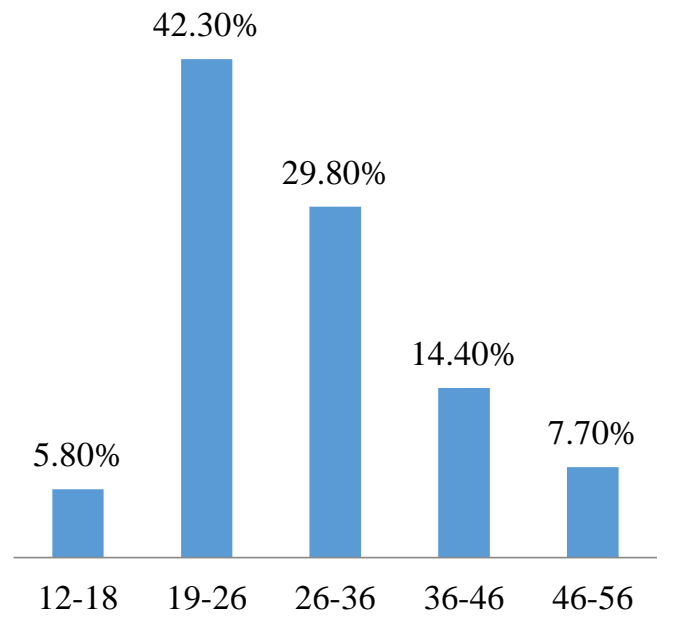

(a)

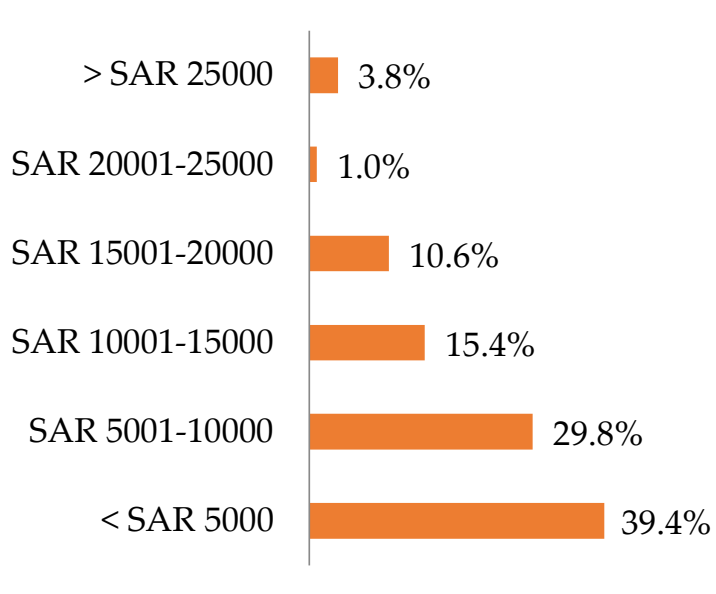

(b)

Figure 5. (a) Age groups and (b) monthly income level of the respondents.
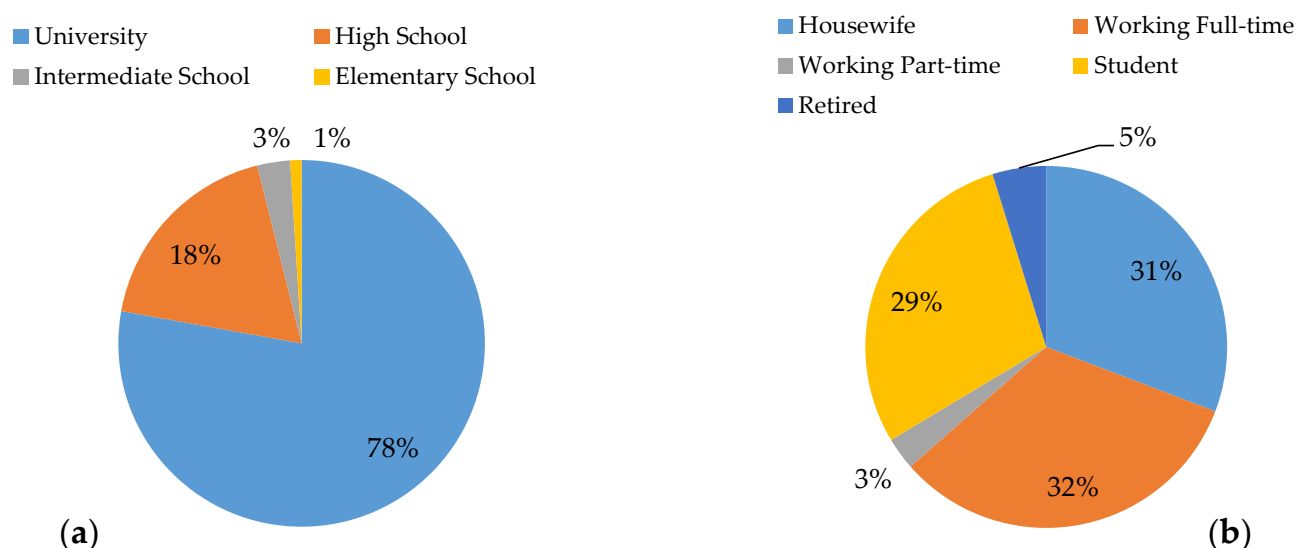

Figure 6. (a) Education level and (b) working status of the respondents.

\subsection{Identification of Women's Mobility Needs within an Urban Settings}

This section represents the current travel behavior and needs of women participants within the urban setting of the DMR. Table 2 shows that most women, irrespective of their occupation, used to travel within the city for a purpose.

Table 2. Cross-tabulation between women's occupation level and preference for travelling within the city.

\begin{tabular}{cccccc}
\hline \multirow{2}{*}{$\begin{array}{c}\text { Travel within } \\
\text { City }\end{array}$} & \multicolumn{5}{c}{ Occupation Level } \\
\cline { 2 - 6 } & Housewife & Working Full-Time & Working Part-Time & Student & Retired \\
\hline Yes & 30 & 33 & 3 & 26 & 4 \\
No & 2 & 1 & 0 & 4 & 1 \\
\hline
\end{tabular}

It reflected the fact that most of the respondents were actively mobile on an everyday basis.

Women had different mobility needs, which led them to have various purpose-driven trips. These trips varied according to their occupations. Figure 7 illustrate the relationship between the mobility purpose of women and their occupations. Trips by homemakers were more wide-ranging, reflecting their varied everyday responsibilities, like escorting children to school, recreational activities, accompanying other dependents out for medical checkups, meeting up their friends and relatives, 
and purchasing groceries. In contrast, full-time and part-time workers traveled mainly for work and escorting their children to schools. Students primarily had trips for their study purposes, recreational activities, and meeting their friends and relatives. Recreational trips were found to be a significant category of trips found for retired women, followed by trips associated with escorting children to school and purchasing of goods and groceries.

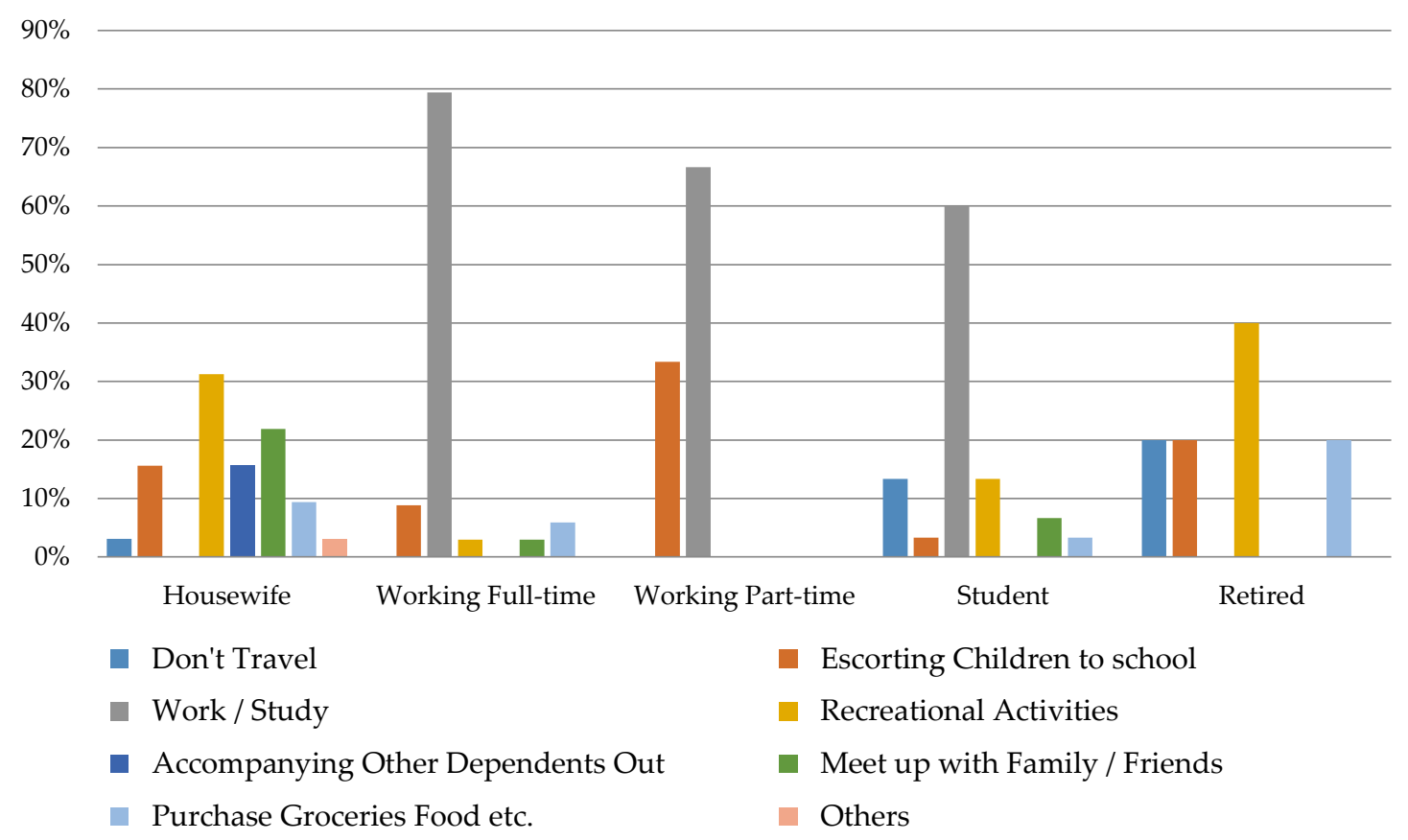

Figure 7. Relationship between women's mobility purpose and their occupation.

Regarding the choice of transport modes in the region, there were only four alternatives: a private motor vehicle, taxi, SAPTCO public bus, and walking. Women's mobility choice highly depended on their daily travel needs, accessibility, and availability. The results of this study showed that $71.4 \%$ of these women have been using private cars for their everyday trips (see Figure 8). The taxi was the second most favorable and frequent traveling mode, and lastly the SAPTCO public bus and walking. Surprisingly, the percentage of women commuting with SAPTCO public buses was negligible in comparison to other choices. Around $56 \%$ of women never used this public bus before, and $20 \%$ did not even take it since last year.

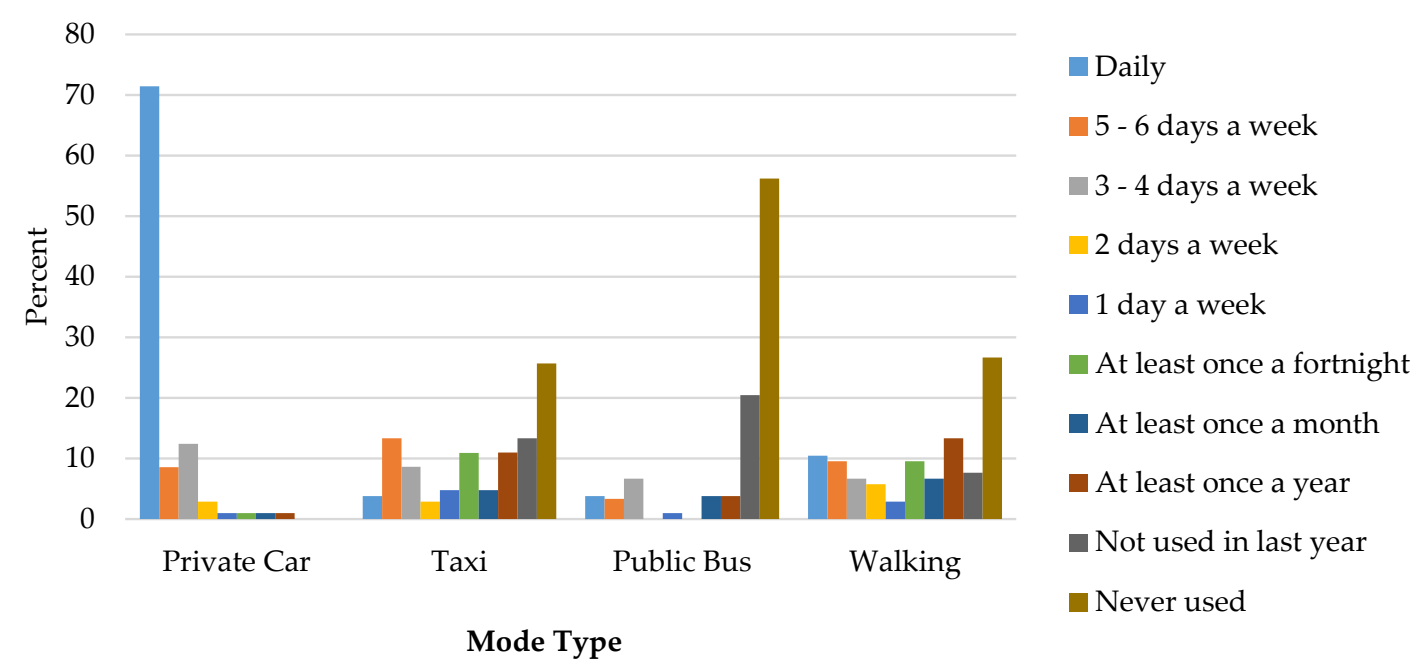

Figure 8. Frequency of women travelling with the different available modes. 
As previously mentioned, the use of a private car is quite common in the Saudi Arabia. Similarly, in the DMR response survey, it was found that $100 \%$ of the households owned private vehicles. As shown in Figure 9, 61\% of the households had more than a single car. Although private household cars were common, it was found that these vehicles were not available for driving for women. Therefore, the availability of these personal vehicles was time-bound, and women were immobile during the working hours of male family members. Approximately $52 \%$ of the women had no access to the private household car during the day, particularly between 09:00 a.m. and 05:00 p.m., which appeared to be a significant barrier to their daily mobility.

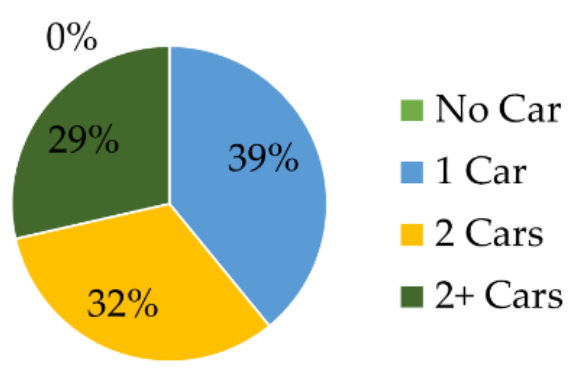

a)

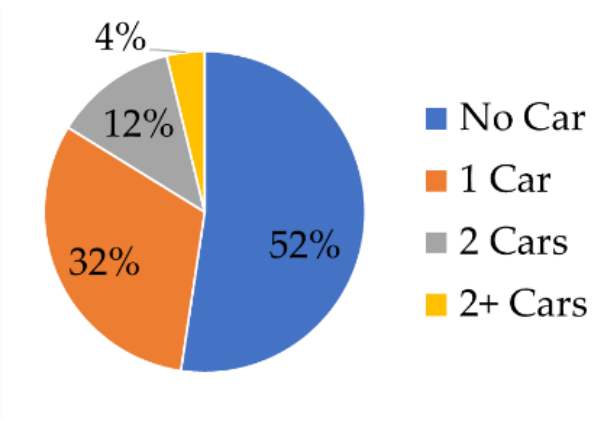

b)

Figure 9. Percentage of (a) owned household private cars and (b) private cars available to women.

During the absence of private vehicles, $48 \%$ of the women did not travel due to a lack of gender-responsive public transit services, while $52 \%$ traveled to meet their daily needs. Among those who traveled, $74.1 \%$ preferred taxis as their second most accessible mode of transport, while only $7.3 \%$ used the SAPTCO public bus. Although walking is not a commonly used travel mode in the Saudi context, it was still more preferred than the public bus. Moreover, $5.6 \%$ of women also used social networks (i.e., cousins, friends, and relatives) to perform trips.

Interviews with taxi drivers further suggested women's travel patterns with taxis. Results indicated that approximately $80 \%$ of women customers were Saudi nationals. The majority of the women taxi users $(85 \%)$ were having trips for shopping, recreation, and work. Women carried out the work-related trips before 09:00 a.m. and shopping trips between 01:00 p.m. and 05:00 p.m. Besides, the most recreational trips were also carried out between 01:00 p.m. and 05:00 p.m. Moreover, it was also found that women's taxi use with adult male family members was significantly low.

\subsection{Comparison of the Gender-Responsive Parameters in Public Transportation: Dammam Metropolitan Region vs. Best Practices}

This section compares the gender-responsive parameters of public transportation in the DMR with the best practices worldwide. The comparison was carried out based on four gender-responsive public transportation indicators, including accessibility, comfort, security, and affordability. Table 3 provides a detailed description of the comparison.

Accessibility is one of the prime concerns in a gender-responsive public transportation system. Certain accessibility features, such as barrier-free walkways to the transit stop, spatial access, and responsive design of the transit vehicles (low-floor vehicles, provision of storage space for baby strollers, and wheelchairs) are a matter of significant concerns for the women population [28,29]. As mentioned earlier, the SAPTCO public bus in the DMR only provides spatial accessibility to a limited area. The results also revealed that it does not have the accessibility features at all. 
Table 3. Comparison of the gender-responsive parameters in public transportation: Dammam Metropolitan Region vs. best practices.

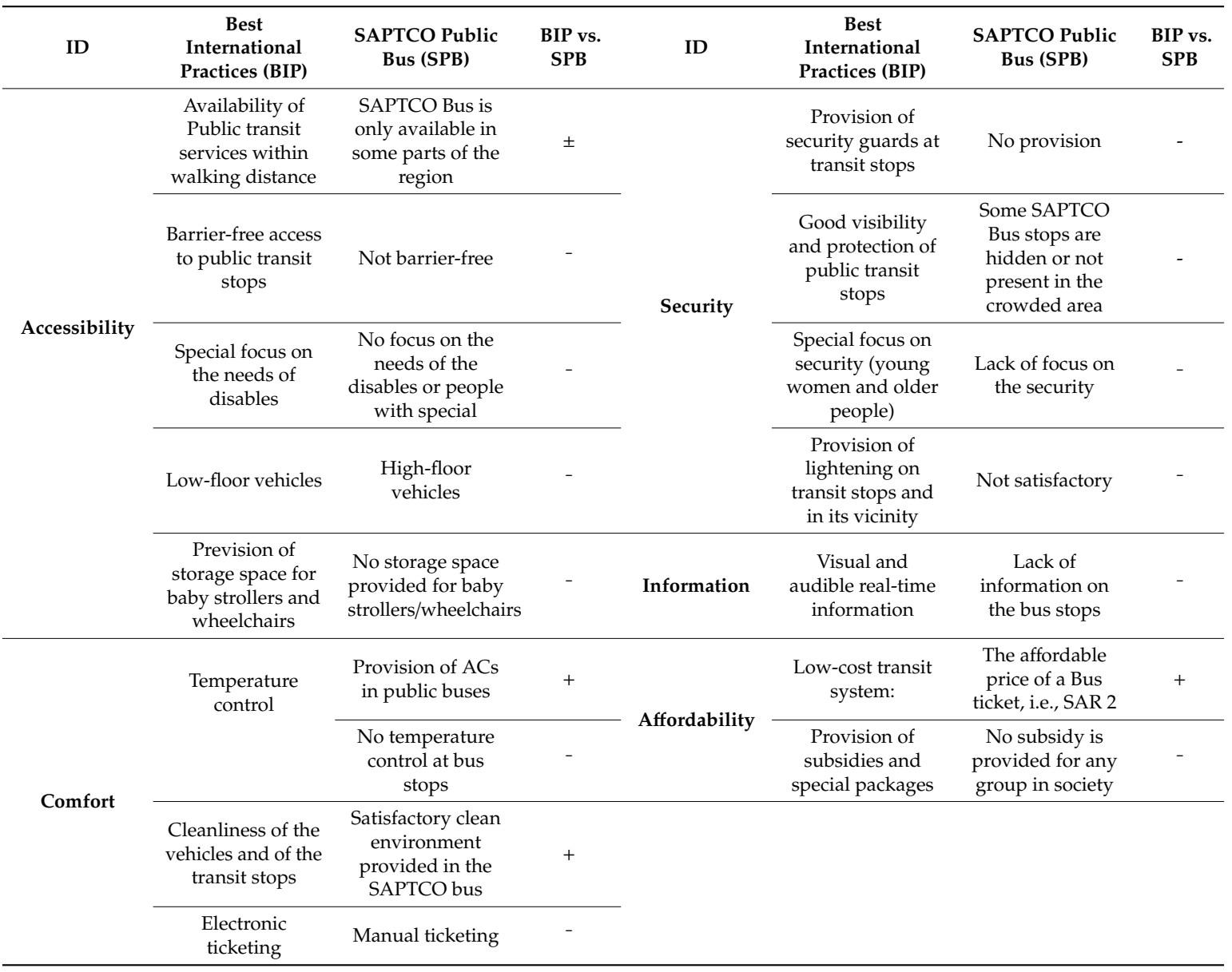

Comfort within public transit vehicles and at the stops are of significant importance for the disadvantaged populations. The relevant comfort-related factors considered include temperature control, cleanliness, and ease of ticketing. Temperature control, especially in the harsh weather like Saudi Arabia, is particularly significant for the women population. However, there are no measures for temperature control at the SAPTCO bus stops while the condition is entirely satisfactory inside the bus. A similar case is observed for the aspect of cleanliness inside the SAPTCO public bus. The findings further suggested that the SAPTCO public bus system does not possess electronic ticketing where customers have to purchase manual tickets during the journey.

Personal security, especially at public transport stops, is another gender-responsive parameter that significantly influences public transport use [24]. The specific security aspects, such as the provision of security guards, lighting, good visibility, and protection of public transport stops, are crucial for the women population. In contrary to international practices, it was found that the SAPTCO public bus stops do not hold any security features. Moreover, there was no audible or visual information for the users at the SAPTCO bus stops, leading to severe constraints while accessing and waiting for the bus.

Finally, affordability of public transportation is also incredibly important for the disadvantaged population, such as women, who generally possess inferior access to private transport modes [21]. Ensuring a low-cost transit system and providing subsidies and special packages to the disadvantaged population groups are critical aspects of affordability in gender-responsive public transportation. This research revealed that the SAPTCO bus ticket is affordable, but there is no special package or subsidy for persons with special needs. 


\subsection{Identification of Mobility Barriers for Women Population}

Based on the field survey, observations, interviews, and statistical analysis, the study has identified the number of barriers that restricted SAPTCO public bus and taxi services usage. The mobility barriers for women were summarized as follows:

1. In the Saudi cultural context, women's privacy is an essential factor for any kind of service. This privacy factor is also a significant barrier for women in using the public bus within the DMR.

- It is found that there is no separate section for women passengers or any seats showing reservations for women in the existing SAPTCO public bus. Such a lack of privacy would not encourage women to use this travel mode.

- Privacy is not only a problem within the bus but also in the waiting area. The SAPTCO public bus stops do not provide any privacy measures for women, such as separate waiting areas and providing separate seats.

- Privacy is also a concern for women while using a taxi, especially when they are traveling alone.

2. Security is a paramount concern that women face while traveling with public buses and taxis, as well as access to these services. Figure 10 shows the level of security of women while using and accessing different available modes. It is apparent that personal safety was at stake with all modes except the private car, i.e., about $88.6 \%$ of women were not worried while using a private vehicle. On the contrary, $34.8 \%$ of the women were anxious, and $34.3 \%$ of women were quite a bit concerned while using and accessing a SAPTCO public bus. The results highlight that the significant reason for making women feel unsafe is poorly maintained buses and bus stops where there are no specific provisions to make them convenient, accessible, and safe.

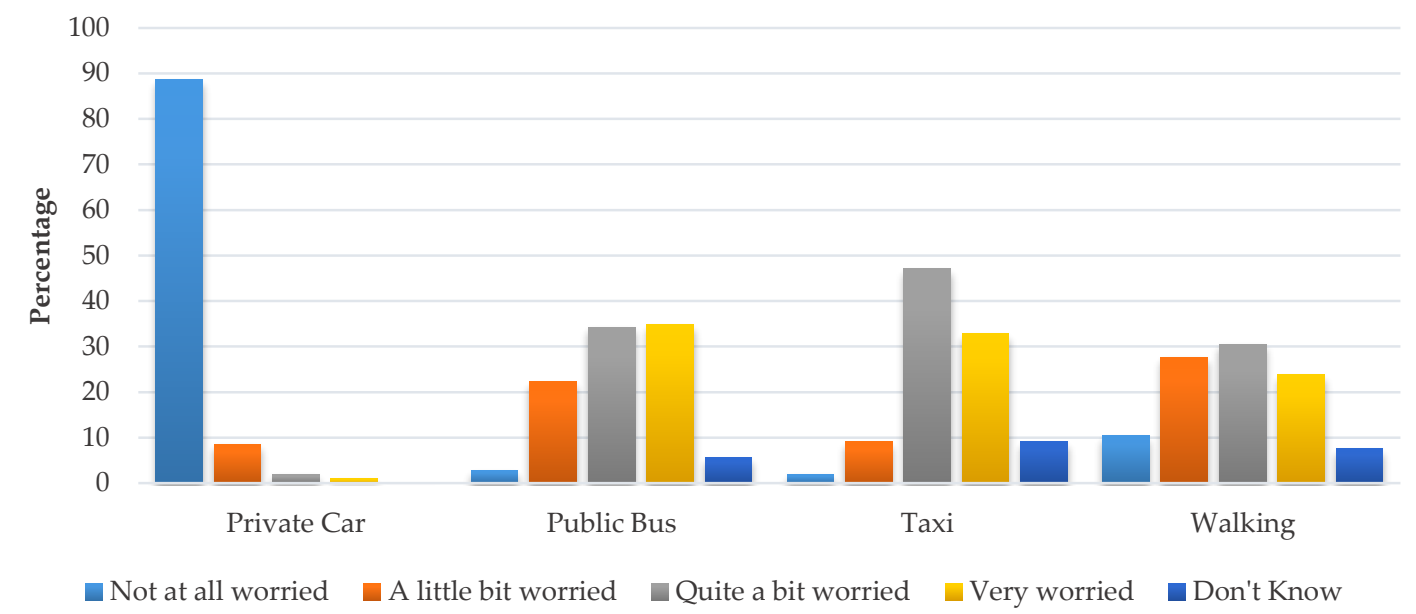

Figure 10. Level of personal security for women associated with the different travelling modes.

In addition to the SAPTCO bus, $80 \%$ of women were concerned and worried about their safety in taxis. Hence, it can be said that the personal security of women in taxis is also at stake. Primarily the main reasons for feeling unsafe were traveling with unknown male drivers whilst being alone, and the privacy in taxis, which ultimately challenge their security. Furthermore, results indicate that women only felt safe when traveling or walking with others to get to the SAPTCO bus.

3. The lack of facilities at the SAPTCO public bus stops was a barrier for women in accessing a public bus:

- There were no waiting rooms or shades at the bus stops. It is difficult to wait in hot weather for the bus even for $5 \mathrm{~min}$, particularly for kids, women, and senior citizens. 
- There was a lack of information at the bus stops, i.e., there was no schedule or route map available to keep the people informed about accurate timing and travel routes, which restricted the women to use the SAPTCO bus.

- The allocated SAPTCO public bus stops were minimal on their route.

4. In addition to the limited coverage of the SAPTCO bus services, the operating hours were also minimal, i.e., the SAPTCO public bus usually operates between 3:00 p.m. and 10:00 p.m., and it has no services for the morning hours. Such unavailability and lack of accessibility hindered the women population from using this bus service because the bus stops are not available within walking distance.

5. The design of the intra-city SAPTCO public bus itself and its supporting infrastructure is not gender-responsive. For instance, the buses were high-floor vehicles, space for baby strollers/wheelchairs in vehicles was absent, and a lack of connecting footpaths for bus stops. Such a lack of focus by these authorities in the provision and improvement of public transport services increases the mobility constraints for the women population.

\subsection{Proposed Gender Audit Prototype Framework}

The concept of gender-responsive public transportation (Section 4.3. and Table 3) was discussed with the authorities. The officials of SAPTCO and the DMR municipality agreed that women's mobility issues had not been considered while designing and operating the SAPTCO public bus. The findings were consistent with the responses of the women participants. Moreover, the officials also acknowledged that the current public transport should be improved to attract women's mobility. Hence, there is a need to encourage and implement a potential gender-responsive public transit system in this region.

The municipality and SAPTCO officials admitted that potential gender-responsive public transportation systems could work in the Saudi Arabian context. Women-only mini-vans, separate sections for women within the public bus, and dial-a-ride women/family-only vehicles were suggested to be implemented into the current system by both authorities and women participants. Thus, the proposed travel modes could attract the women population and enhance their independent mobility.

Given the proposals of the women respondents and transport policymakers, the study suggests the following strategies to be implemented to overcome the barriers to women's mobility:

1. Security, which is the prime concern for women while accessing the public transport system, should be improved by establishing CCTVs and security guarding.

2. With a walking distance of up to $500 \mathrm{~m}$, the extended public bus routes should be planned and implemented, having operating hours between 07:00 a.m. and 10:00 p.m.

3. According to daily travel needs, more public buses should be operated for women or families, mainly from 10:00 a.m. to 05:00 p.m.

4. SAPTCO currently provides special inter and intra-city transport services, including limousine and school buses. Therefore, dial-a-ride services can be provided by SAPTCO, particularly for women who tend to use mini-vans rather than the sedan-type cars. The online and phone booking facilities should be improved. SAPTCO can plan the routes based on the requests and direct the vans to specific neighborhoods.

5. Separate sections for women within public buses can eliminate privacy and security concerns. Consequently, this can attract women towards the public bus.

6. Buses should be redesigned with more accessible facilities for women who often travel with their children. Additionally, a specific space for baby strollers should be reserved.

7. The bus stops should be designed appropriately to provide comfortable sitting facilities with suitable shade to protect users from harsh weather. The routes should also be illustrated, which could also improve accessibility. 


\section{Discussion and Conclusions}

The demand for mobility of women and its characteristics are gaining attention in the organization of mobility services and, more generally, in urban policies. On one hand, there is a sheer lack of understanding about the relationship between gender needs and women's current mobility; on the other, there are evident signs of the growing interest and willingness to deal with this issue to develop more sustainable transportation that is responsive to gender needs.

This research shows how socio-cultural parameters can influence travel choices, motivations, and inequality with mobility. In particular, these differences result from structural elements (the condition of women in the labor market) and relative to the social context (role of women in the family). Specifically, the results obtained made it possible to analyze the choice of mobility within the DMR considering the evolution that is taking place over the years, reducing the inequalities between the genders that were highlighted in the literature by [50,51].

The survey was carried out in selected parts of the Dammam region in Saudi Arabia, so these results cannot be generalized to the entire population living in other parts of the region. However, they can provide an opportunity to encourage collaboration between administrations and citizens in evaluating the best travel choices and the critical issues that each user highlights as the modes of transport change. The study presented is the first step of an investigation in which the sample size and online sampling technique were justified by the limited time, resources, finances, and social barriers necessary to approach all women. Research has shown that women in the DMR have various tasks and responsibilities associated with their occupation, which affects the choice of medium.

In several regions of Saudi Arabia, Saudi women are still unable to drive and therefore rely on private drivers, husbands, brothers, children, or other close relatives to take them to work [45]. The issuance of the Royal Decree on women's driving in May 2018 has drawn the attention to mobility. It encourages fairness and, at the same time, increases the freedom of travel choice without having to rely on the presence of a companion. However, this freedom deriving from the results still has limitations depending on the time slots. Since there are still not many women with driving licenses, taxis are a preferential transportation choice because they are readily available. They are used to meet mobility needs, and the results have shown that most women travel alone or with their children. These findings are in line with previous research $[44,48]$. The points that emerged concern the need to facilitate access, make public transport stops safe, and adapt the interior fittings of public transport vehicles to the needs of women.

Concerning taxi transshipment, the creation of on-demand services or the promotion of "pink" taxis, driven by the women drivers at discounted rates at night and in the evening, can encourage travel. Targeted analyses on the subject can develop elements of knowledge and expand the statistical base (to know the demand for mobility disaggregated by gender), adopt gender assessment schemes in transport planning tools, promote research and knowledge of the topic, and affirming the presence of women in the governance of transport companies and the structures of public administration. These results may encourage the analysis and implementation of some on-demand taxi services. The results also showed that most women travel by taxi without men, especially in the early afternoon for shopping and leisure, which in some cases leads to privacy and security issues.

As far as public transport is concerned, it was noted that there is currently no gender-responsive public transport in the DMR. Therefore, through the second phase of analysis with an increase in the number of users interviewed, it will be possible to evaluate which variables can improve the public transport service intra-city, considering both gender equality and the need to maintain social distancing due to pandemic events. The emerging smart mobility system, such as demand-oriented, women-only, self-driving mini-buses and vans, could be essential mobility choices in the wake of COVID-19. Consequently, public transport can be made more efficient, adaptable, interchangeable, and diversified with spatial-temporal coordination and real-time data analysis through the implementation of ITS systems and/or periodic survey campaigns. These improvements can allow women to use public 
transport while enhancing their independent mobility and equality to get access to public transportation based on the gender needs.

This research demonstrated the importance of a larger and more comprehensive study, including gender auditing for the existing transport system in socio-cultural regions similar to the case study area. It would close the gaps between all the stakeholders who are accountable as policymakers, planners, and transport providers in order to (re-)develop sustainable public transportation. For Saudi Arabia, being a developing country, the lessons of this study would be critical to other developing nations where women face inequality in getting access to public transportation as per their daily needs. The findings of this study are also equally applicable to rural areas and remote regions where gender-based needs are key in designing sustainable transportation for all.

Author Contributions: Conceptualization, M.A.A.-R., K.M.N. and T.C.; methodology, M.A.A.-R., K.M.N., S.A. and T.C.; software, M.A.A.-R.; validation, K.M.N.; formal analysis, M.A.A.-R., K.M.N., S.A. and T.C.; resources, K.M.N.; data curation, M.A.A.-R.; writing—original draft preparation, M.A.A.-R., K.M.N. and S.A.; writing一review and editing, M.A.A.-R., K.M.N., S.A., T.C. and N.A.; supervision, K.M.N. and N.A.; project administration, K.M.N. and T.C.; funding acquisition, T.C. All authors have read and agreed to the published version of the manuscript.

Funding: This research work was funded by the MIUR (Ministry of Education, Universities and Research [Italy]) through a project entitled WEAKI TRANSIT: WEAK-demand areas Innovative TRANsport Shared services for Italian Towns (Project code: 20174ARRHT/CUP Code:J74I19000320008) PRIN 2017 (Research Projects of National/Relevance) program Italy.

Acknowledgments: The authors acknowledge financial support from the MIUR (Ministry of Education, Universities and Research [Italy]) through a project entitled WEAKI TRANSIT: WEAK-demand areas Innovative TRANsport Shared services for Italian Towns (Project code: 20174ARRHT/CUP Code: J74I19000320008), financed with the PRIN 2017 (Research Projects of National Relevance) program. We authorize the MIUR to reproduce and distribute reprints for Governmental purposes, notwithstanding any copyright notations thereon. Any opinions, findings, and conclusions or recommendations expressed in this material are those of the authors and do not necessarily reflect the views of the MIUR.

Conflicts of Interest: The authors declare no conflict of interest.

\section{References}

1. Rajé, F. The Lived Experience of Transport Structure: An Exploration of Transport's Role in People's Lives. Mobilities 2007, 2, 51-74. [CrossRef]

2. Urban Mobilities in the Global South. Urban Mobilities in the Global South; Routledge: New York, NY, USA, 2017.

3. Doughty, K.; Murray, L. Discourses of Mobility: Institutions, Everyday Lives and Embodiment. Mobilities 2014, 11, 303-322. [CrossRef]

4. Cubells, J.; Marquet, O.; Miralles-Guasch, C. Gender and Age Differences in Metropolitan Car Use. Recent Gender Gap Trends in Private Transport. Sustainability 2020, 12, 7286. [CrossRef]

5. Iqbal, S.; Woodcock, A.; Osmond, J. The effects of gender transport poverty in Karachi. J. Transp. Geogr. 2020, 84, 102677. [CrossRef]

6. UN-HABITAT. Mobility as Access: Equitable Urban Mobility; United Nations Headquarters: New York, NY, USA, 2014.

7. Das, A.K. Gender-Responsive Public Transport. Encycl. UN Sustain. Dev. Goals 2019, 1-12. [CrossRef]

8. Uteng, T.P.; Turner, J. Addressing the Linkages between Gender and Transport in Low- and Middle-Income Countries. Sustainability 2019, 11, 4555. [CrossRef]

9. Maciejewska, M.; Marquet, O.; Miralles-Guasch, C. Changes in gendered mobility patterns in the context of the Great Recession (2007-2012). J. Transp. Geogr. 2019, 79, 102478. [CrossRef]

10. Al-Qarawi, N.; Kamargianni, M.; Matyas, M. She Drives KSA-Phase 1 Survey Report; IAU: Dammam, Saudi Arabia, 2018.

11. AlShabibi, N. A Priminalry Determination of Factors Effecting Female Travel Demand, Pattern, and Behavior in the Kingdom of Saudi Arabia. Int. J. Psychosoc. Rehabil. 2019, 23, 11-20. [CrossRef]

12. Clarke, M. Making Transport Work for Women and Men: Challenges and Opportunities in the Middle East and North Africa (MENA) Region-Lessons from Case Studies; World Bank Group: Washington, DC, USA, 2012. 
13. Simms, E.-M.; Stawarska, B. Introduction: Concepts and methods in interdisciplinary feminist phenomenology. Janus Head 2013, 13, 6-16.

14. Jensen, O.B. Flows of Meaning, Cultures of Movements - Urban Mobility as Meaningful Everyday Life Practice. Mobilities 2009, 4, 139-158. [CrossRef]

15. UNESCAP. Gender and Transport; Report Congestion Combatting No. 76, No.82; Economic and Social Commission for Asia and the Pacific Transport and Communications Bulletin for Asia and the Pacific: Bangkok, Thailand, 2013.

16. Richardson, B.C. Sustainable transport: Analysis frameworks. J. Transp. Geogr. 2005, 13, 29-39. [CrossRef]

17. Ogryzek, M.; Adamska-Kmieć, D.; Klimach, A. Sustainable Transport: An Efficient Transportation Network-Case Study. Sustainability 2020, 12, 8274. [CrossRef]

18. UN-Women. Safe Cities Free of Violence against Women and Girls Programme; UN Women/Safe Cities Global Programme: New Dehli, India, 2009.

19. UNICEF. Gender Equality Glossary of Terms and Concepts; UNICEF: Kathmandu, Nepal, 2017.

20. ArrayExpress-A Database of Functional Genomics Experiments. Available online: http://www.ebi.ac.uk/ arrayexpress/ (accessed on 12 November 2012).

21. Basarić, V.; Vujičić, A.; Simić, J.M.; Bogdanović, V.; Saulić, N. Gender and Age Differences in the Travel Behavior-A Novi Sad Case Study. Transp. Res. Procedia 2016, 14, 4324-4333. [CrossRef]

22. Peters, D. Gender and Sustainable Urban Mobility Thematic Study Prepared for Global Report on Human Settlements; United Nations: Nairobi, Kenya, 2013; Available online: https:/unhabitat.org/wp-content/uploads/2013/06/ GRHS (accessed on 6 September 2012).

23. Uteng, T.P. Gender and Mobility in the Developing World, background paper of World Development Report 2012-Gender Equality and Development; World Bank: Washington, DC, USA, 2011.

24. Law, R. Beyond 'women and transport': Towards new geographies of gender and daily mobility. Prog. Hum. Geogr. 1999, 23, 567-588. [CrossRef]

25. Mazumder, H.; Pokharel, B. Sexual Violence on Public Transportation: A Threat to Women's Mobility in Bangladesh. J. Aggress. Maltreatment Trauma 2018, 28, 1017-1019. [CrossRef]

26. Beall, J. Urban governance: Why Gender Matters; UNDP: New York, NY, USA, 1996.

27. Shirwani, R.; Gulzar, S.; Asim, M.; Umair, M.; Al-Rashid, M.A. Control of vehicular emission using innovative energy solutions comprising of hydrogen for transportation sector in Pakistan: A case study of Lahore City. Int. J. Hydrogen Energy 2020, 45, 16287-16297. [CrossRef]

28. Greed, C. Overcoming the Factors Inhibiting the Mainstreaming of Gender into Spatial Planning Policy in the United Kingdom. Urban Stud. 2005, 42, 719-749. [CrossRef]

29. Cresswell, T. Gendered mobilities in developing countries: The case of (urban) Uganda. In Gendered Mobilities; Routledge: London, UK, 2016; pp. 173-186.

30. Greed, C. Women and Minorities Planning: The Next Steps. C. Greed Introducing Planning; Continuum: London, UK, 2000; pp. 197-210.

31. Gordon, P.; Kumar, A.; Richardson, H.W. Gender Differences in Metropolitan Travel Behaviour. Reg. Stud. 1989, 23, 499-510. [CrossRef]

32. Hanson, J.; Bichard, J.; Greed, C. Access to the Built Environment: Barriers, Chains and Missing Links: Initial Review; University of the West of England: Bristol, UK, 2004.

33. Lu, X.; Pas, E.I. Socio-demographics, activity participation and travel behavior. Transp. Res. Part A Policy Pr. 1999, 33, 1-18. [CrossRef]

34. Bianco, M.; Lawson, C. Trip chaining, childcare and personal safety: Critical issues in women's travel behavior. In Proceedings of the Second National Conference on Women's Travel Issues, Baltimore, Maryland, October 1996; US Department of Transportation, Federal Highway Administration: Washington, DC, USA, 1996.

35. UN-HABITAT. The State of Arab Cities 2012: Challenges of Urban Transition; UN Habitat: Nairobi, Kenya, 2012.

36. Skidmore, P.; Craig, J. The Art of Association: Community Organisation and the Public Realm; a Literature Review Conducted as Part of a Demos/New Opportunities Fund Project on Participation, Inclusion and Service Delivery; Demos: London, UK, 2004.

37. UN-HABITAT. Gender Issue Guide. Urban Planning and Design; Miller, E., Ed.; United Nations Human Settlements Programme: Nairobi, Kenya, 2012. 
38. Damyanovic, D.; Reinwald, F.; Weikman, A. Gender Mainstreaming in Urban Planning E Urban Development; Urban Development Vienna; Municipal Department 18 (MA 18)-Urban Development and Planning: Vienna, Austria, 2013.

39. Alotaibi, O.; Potoglou, D. Introducing public transport and relevant strategies in Riyadh City, Saudi Arabia: A stakeholders' perspective. Urban Plan. Transp. Res. 2018, 6, 35-53. [CrossRef]

40. Al-Dubikhi, S.A. Exploring the Potential for Successful Public Transport in Riyadh; University of Melbourne: Melbourne, Australia, 2007.

41. Al-Atawi, A.M. Sustainable Transportation in Saudi Arabia: Reducing Barriers and Choosing Values. Int. J. Transp. 2015, 3, 81-88. [CrossRef]

42. Global Mass Transit, G. Policy Review; Public transport in Saudi Arabia, Embracing comprehensive mobility. Available online: https://www.globalmasstransit.net/archive.php?id=6463 (accessed on 30 September 2020).

43. Rahman, M.T.; Nahiduzzaman, K.M. Examining the Walking Accessibility, Willingness, and Travel Conditions of Residents in Saudi Cities. Int. J. Environ. Res. Public Health 2019, 16, 545. [CrossRef] [PubMed]

44. Errigo, M.F.; Tesoriere, G. Urban Travel Behavior Determinants in Saudi Arabia. TeMA J. Land Use Mobil. Environ. 2018, 31-46. [CrossRef]

45. Peterson, H.P.; Al Kassim, Z. A case study on perceptions of public transportation in the eastern province of saudi arabia. Transp. Probl. 2020, 15, 5-15. [CrossRef]

46. Assi, K.J.; Shafiullah, M.; Nahiduzzaman, K.M.; Mansoor, U. Travel-To-School Mode Choice Modelling Employing Artificial Intelligence Techniques: A Comparative Study. Sustainability 2019, 11, 4484. [CrossRef]

47. Canale, A.; Campisi, T.; Tesoriere, G.; Sanfilippo, L.; Brignone, A. The Evaluation of Home-School Itineraries to Improve Accessibility of a University Campus Trough Sustainable Transport Modes. In Computational Science and Its Applications-ICCSA 2020. ICCSA 2020. Lecture Notes in Computer Science; Gervasi, O., Murgante, B., Misra, S., Garau, C., Ivan, B., Taniar, D., Apduhan, B.O., Rocha, A., Tarantino, E., Torre, C.M., et al., Eds.; Springer: Cham, Switzerland, 2020; Volume 12250. [CrossRef]

48. Assi, K.J.; Nahiduzzaman, K.M.; Ratrout, N.T.; Aldosary, A.S. Mode choice behavior of high school goers: Evaluating logistic regression and MLP neural networks. Case Stud. Transp. Policy 2018, 6, 225-230. [CrossRef]

49. Nihal, M. Women Express Concern over 'no Hailing Taxi' Law, in Saudi Women Driving; Saudi Gazette: Jeddah, Saudi Arabia, 2013.

50. AlMunajjed, M. Women's Education in Saudi Arabia: The Way Forward; Booz \& Company: New York, NY, USA, 2009; Volume 1, p. 23.

51. Jabeen, S.; Haq, S.; Jameel, A.; Hussain, A.; Asif, M.; Hwang, J.; Jabeen, A. Impacts of Rural Women's Traditional Economic Activities on Household Economy: Changing Economic Contributions through Empowered Women in Rural Pakistan. Sustainability 2020, 12, 2731. [CrossRef]

Publisher's Note: MDPI stays neutral with regard to jurisdictional claims in published maps and institutional affiliations.

(C) 2020 by the authors. Licensee MDPI, Basel, Switzerland. This article is an open access article distributed under the terms and conditions of the Creative Commons Attribution (CC BY) license (http://creativecommons.org/licenses/by/4.0/). 